\title{
RELATIONSHIP BETWEEN LANDCOVER PATTERN AND SURFACE NET RADIATION IN AN COASTAL CITY
}

\author{
X. Zhao ${ }^{\mathrm{a}, *}$, L. Liu ${ }^{\mathrm{a}, \mathrm{b}}, \mathrm{X} . \mathrm{Liu}^{\mathrm{c}}$, Y. Zhao ${ }^{\mathrm{a}}$ \\ ${ }^{\text {a }}$ Key Lab of Urban Environment and Health, Institute of Urban Environment, Chinese Academy of Sciences, 361021Xiamen, \\ China-(xfzhao, llliu,yczhao)@iue.ac.cm \\ ${ }^{\mathrm{b}}$ University of Chinese Academy of Sciences, 100049 Beijing, China \\ c China University of Geosciences, 430074 Wuhan, China-xgliu66@163.com \\ Commission VIII, WG VIII/8
}

KEY WORDS: Surface net radiation, Land covers pattern, Landscape metrics, Correlation analysis, Stepwise regression, Xiamen city

\begin{abstract}
:
Taking Xiamen city as the study area this research first retrieved surface net radiation using meteorological data and Landsat 5 TM images of the four seasons in the year 2009. Meanwhile the 65 different landscape metrics of each analysis unit were acquired using landscape analysis method. Then the most effective landscape metrics affecting surface net radiation were determined by correlation analysis, partial correlation analysis, stepwise regression method, etc. At both class and landscape levels, this paper comprehensively analyzed the temporal and spatial variations of the surface net radiation as well as the effects of land cover pattern on it in Xiamen from a multi-seasonal perspective. The results showed that the spatial composition of land cover pattern shows significant influence on surface net radiation while the spatial allocation of land cover pattern does not. The proportions of bare land and forest land are effective and important factors which affect the changes of surface net radiation all the year round. Moreover, the proportion of forest land is more capable for explaining surface net radiation than the proportion of bare land. So the proportion of forest land is the most important and continuously effective factor which affects and explains the cross-seasonal differences of surface net radiation. This study is helpful in exploring the formation and evolution mechanism of urban heat island. It also gave theoretical hints and realistic guidance for urban planning and sustainable development.
\end{abstract}

\section{INTRODUCTION}

In recent years, the global process of urbanization has been progressing more and more quickly, thus causing many problems for the urban environment and climate, which have drawn the attention of the whole world (Grimm, 2007). Land cover changes caused by urbanization alter the energy budget and balance of land surface, thus contribute to the phenomenon of urban heat island. It has been proved that differences in surface land cover lead to varieties of surface net radiation (Arnfield, 2003; Liu, 2012). However, previous researches on the relationship between land cover pattern and surface net radiation are all carried out in one single season. So what are the factors of land cover pattern which can affect surface net radiation stably and significantly across seasons of the whole year? These factors selected out would be more valid, appropriate and meaningful for urban planning practice. Taking Xiamen city as the study area, this research investigated the relationship between remote sensing retrieved surface net radiation and land cover pattern across seasons to find the factors.

\section{STUDY AREA}

Xiamen is a typical coastal city located on the southeast coast of Fujian province, China, facing the Taiwan Strait $\left(24^{\circ} 25^{\prime}-\right.$ $24^{\circ} 55^{\prime} \mathrm{N}, 117^{\circ} 53^{\prime}-118^{\circ} 27^{\prime} \mathrm{E}$ )( Figure 1). The city has a land area of $1,573 \mathrm{~km}^{2}$, a sea area of $390 \mathrm{~km}^{2}$, and a population of 3.67 million in 2012 (Xiamen Bureau of Statistics, 2013). It has a subtropical climate, with annual average rainfall of $1100 \mathrm{~mm}$ and annual average temperature of $21^{\circ} \mathrm{C}$ ) (Zhao, 2010a). In
1980, it was designated as one of the five Special Economic Zones with the implementation of reform and opening-up policy in China. Since then, Xiamen has undergone rapid urbanization and its urban population and built-up area grew at an unprecedented speed. The urban built-up area increased from 12 $\mathrm{km}^{2}$ in 1981 to $264 \mathrm{~km}^{2}$ in 2012 (Xiamen Bureau of Statistics, 2013). Meanwhile, the surface UHI in Xiamen grew significantly in both spatial extent (from $14 \mathrm{~km}^{2}$ to $160 \mathrm{~km}^{2}$ ) and intensity (from $2^{\circ} \mathrm{C}$ to more than $10^{\circ} \mathrm{C}$ ) during the past twenty years (1987 to 2007) (Zhao, 2010b).

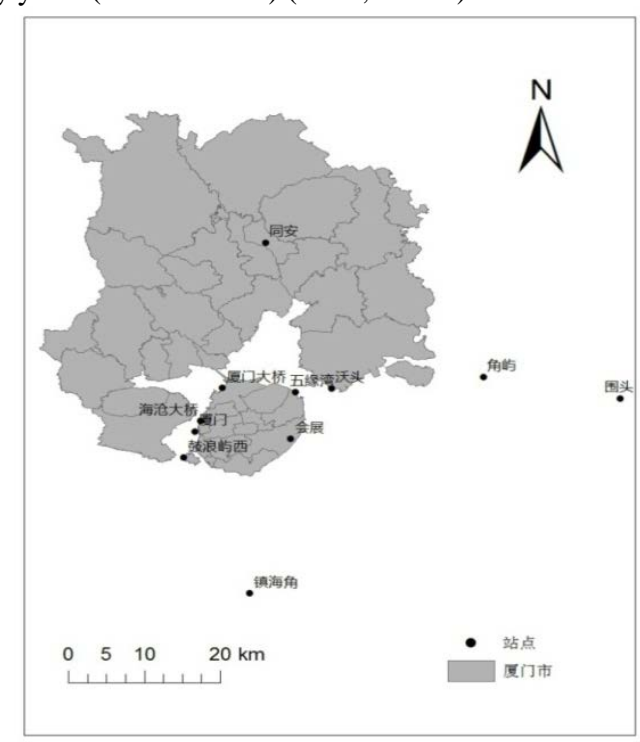

Figure 1. Study area and meteorological stations

* Corresponding author 


\section{DATA AND METHODS}

\subsection{Data}

This research retrieved surface net radiation using meteorological data of 11 ground stations (Figure 1) and four Landsat 5 TM images of each season in the year 2009. The dates of TM images are 2009/01/13, 2009/03/18, 2009/06/06 and 2008/11/10 respectively. All these images were acquired around 10 a.m. local time under clear weather conditions. They were geo-referenced to the Universal Transverse Mercator projection system (Zone N50). And their thermal bands were resampled to $30 \mathrm{~m}$ resolution using the nearest neighbor algorithm.

\subsection{Land Cover Classification}

Six reflected bands, band 1 through band 5 and band 7, were used to acquire land cover on different dates via supervised classification, adjusted with the same criterion in our previous study in this area (Zhao, 2010b). Six land cover types were included in the final classified images: (1) built-up area, (2) bare soil, (3) water, (4) farmland, (5) forest, and (6) tidal flat.

\subsection{Retrieval of Surface Net Radiation}

The retrieval method of surface net radiation is derived from the papers (Yamaguchi and Kato, 2005; 2012) and based on the equation of urban surface balance.

$$
R_{n}=(1-\alpha) R_{S}+\varepsilon_{s} \cdot R_{L \downarrow}-R_{L \uparrow}
$$

where $R_{n}=$ net radiation absorbed by the ground surface

$\mathrm{R}_{\mathrm{S}}=$ shortwave radiation

$\mathrm{R}_{\mathrm{L}} \downarrow=$ downward longwave radiations

$\mathrm{R}_{\mathrm{L}} \uparrow=$ upward longwave radiations

$a=$ surface albedo

$\varepsilon_{s}=$ surface emissivity

Longwave radiation is calculated using the Stefan - Boltzmann law.

3.3.1 Surface Albedo: Surface albedo was acquired using the classic method in paper (Liang, S., 2001).

$\alpha=0.356 \rho_{1}+0.130 \rho_{3}+0.373 \rho_{4}+0.085 \rho_{5}+0.072 \rho_{7}-0.0018$

where $\rho_{i}=$ apparent reflectance on top of atmosphere for the ith band

3.3.2 Surface Emissivity: Surface emissivity was deprived from related lookup tables according to the land cover types.

3.3.3 Atmospheric Emissivity: Atmospheric emissivity was deprived through method in paper (Yamaguchi and Kato, 2005).

$$
\varepsilon_{a}=1.24\left(\frac{e_{a}}{T_{a}}\right)^{1 / 7}
$$

where $\varepsilon_{\mathrm{a}}=$ atmospheric emissivity

$\mathrm{e}_{\mathrm{a}}=$ atmospheric water vapor pressure

$\mathrm{T}_{\mathrm{a}}=$ the atmospheric temperature

3.3.4 Downward and Upward Longwave Radiations: Downward and upward longwave radiations were calculated using the Stefan - Boltzmann law.

$$
\begin{aligned}
& \mathrm{R}_{\mathrm{L}} \downarrow=\varepsilon_{\text {a }} \sigma \mathrm{T}_{\mathrm{a}}{ }^{4} \\
& \mathrm{R}_{\mathrm{L}} \uparrow=\varepsilon \quad \sigma \mathrm{T}_{\mathrm{S}}{ }^{4}
\end{aligned}
$$

\subsection{Landscape Metrics}

Township was used as the basic analytical unit in this study. The municipality of Xiamen has a total of 37 townships, and 4 standalone forest farms with relatively large scale. Thus there were overall 41 analytical units in this study (Figure 1). 65 different landscape metrics of each analysis unit were acquired using landscape analysis method. They included 11 landscapelevel metrics and 9 class-level metrics for each of the six land cover classes (Table 1).

\begin{tabular}{|l|l|l|}
\hline Abbreviation & \multicolumn{1}{|c|}{ Metrics } & \multicolumn{1}{c|}{ Level } \\
\hline PLAND & $\begin{array}{l}\text { Landscape } \\
\text { classes percent }\end{array}$ & Class \\
\hline PD & Patch density & Class, landscape \\
\hline LPI & $\begin{array}{l}\text { Largest patch } \\
\text { index }\end{array}$ & Class, landscape \\
\hline ED & Edge density & Class, landscape \\
\hline LSI & $\begin{array}{l}\text { Landscape shape } \\
\text { index }\end{array}$ & Class, landscape \\
\hline AREA_MN & Mean patch size & Class, landscape \\
\hline SHAPE_MN & $\begin{array}{l}\text { Mean patch } \\
\text { shape index }\end{array}$ & Class, landscape \\
\hline ENN_MN & $\begin{array}{l}\text { Mean Euclidean } \\
\text { nearest-neighbor } \\
\text { distance }\end{array}$ & Class, landscape \\
\hline COHESION & $\begin{array}{l}\text { Patch cohesion } \\
\text { index }\end{array}$ & Class, landscape \\
\hline CONTAG & Contagion index & landscape \\
\hline SHDI & $\begin{array}{l}\text { Shannon's } \\
\text { diversity index }\end{array}$ & landscape \\
\hline SHEI & $\begin{array}{l}\text { Shannon's } \\
\text { evenness index }\end{array}$ & landscape \\
\hline
\end{tabular}

Table 1. Landscape metrics used in this study.

\subsection{Landscape Metrics}

Then the most effective landscape metrics affecting surface net radiation were determined by correlation analysis, partial correlation analysis, stepwise regression method, etc. We first used Pearson correlations to explore the bivariate relationships between surface net radiation and landscape metrics across all the analytical units and seasons. If the correlation coefficients between surface net radiation and a certain metric could keep significant for all the four seasons, we considered this metric to be a consistently significant factor in the landscape patternsurface net radiation relationship. By means of this rule, all the consistently significant factors for each year were primarily selected out at the end of this procedure.

Since bivariate analysis did not consider the inter-correlations between variables, it might result in spurious correlations between surface net radiation and some landscape metrics. So we further carried out partial Pearson correlation analysis to examine the relationship between surface net radiation and landscape metrics. In partial Pearson correlation analysis, composition metrics, i.e. PLAND, were taken as the controlled variables prior to configuration metrics, e.g. LPI, under the same consistently significant circumstances. This was owing to previous studies which proved that landscape composition is more important in explaining LST variations than configuration (Zhou, et al. 2011; Li, et al. 2013). All statistical analyses were implemented using SPSS 16.0. 


\section{RESULTS}

\subsection{Seasonal Variations of Surface Net Radiation}

The results showed that Xiamen's surface net radiation is the maximum in summer, followed by spring, autumn (Figure 2). The surface net radiation in winter is the minimum. Net radiation flux is higher for the land cover types of water and forestland, while is lower for built-up land and bare land, etc.

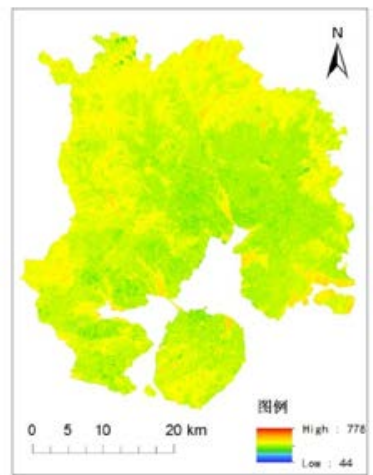

(a)spirng

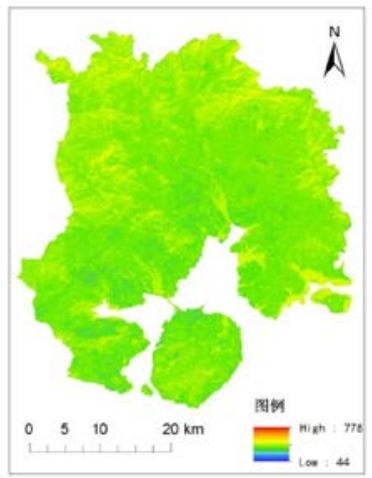

(c)autumn

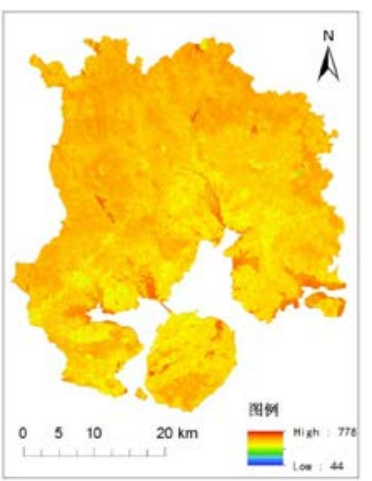

(b)summer

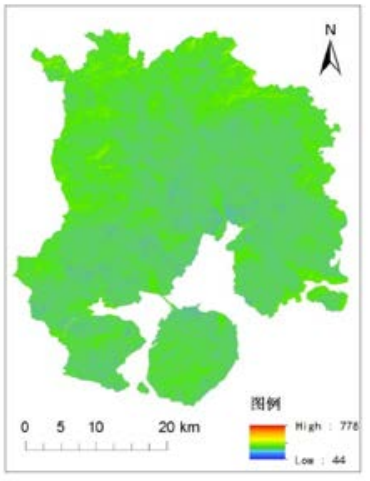

(b)winter
Figure 2. Surface net radiation of Xiamen in the year 2009

\subsection{Pearson Correlation Analysis across Seasons}

Since the complete table is quite huge, only metrics which have consistently significant correlations with surface net radiation are listed in Table 2. Most of the consistently significant factors belong to class 2 and class 5, which are bare land and forest respectively.

\begin{tabular}{|l|r|r|r|r|}
\hline \multicolumn{1}{|c|}{ Metrics } & \multicolumn{1}{c|}{ autumn } & \multicolumn{1}{c|}{ winter } & \multicolumn{1}{c|}{ spring } & \multicolumn{1}{c|}{ summer } \\
\hline ED1 & $-.720^{* *}$ & $-.584^{* *}$ & $-.345^{*}$ & $-.647^{* *}$ \\
\hline COHESION1 & $-.560^{* *}$ & $-.529^{* *}$ & $-.363^{*}$ & $-.624^{* *}$ \\
\hline PLAND2 & $-.579^{* *}$ & $-.694^{* *}$ & $-.698^{* *}$ & $-.504^{* *}$ \\
\hline PD2 & $-.658^{* *}$ & $-.592^{* *}$ & $-.648^{* *}$ & $-.684^{* *}$ \\
\hline LPI2 & $-.495^{* *}$ & $-.617^{* *}$ & $-.661^{* *}$ & $-.426^{* *}$ \\
\hline ED2 & $-.666^{* *}$ & $-.702^{* *}$ & $-.695^{* *}$ & $-.605^{* *}$ \\
\hline PLAND5 & $.661^{* *}$ & $.741^{* *}$ & $.620^{* *}$ & $.695^{* *}$ \\
\hline LPI5 & $.692^{* *}$ & $.751^{* *}$ & $.611^{* *}$ & $.681^{* *}$ \\
\hline AREA_MN5 & $.488^{* *}$ & $.552^{* *}$ & $.444^{* *}$ & $.586^{* *}$ \\
\hline AREA_MN & $.640^{* *}$ & $.647^{* *}$ & $.426^{* *}$ & $.613^{* *}$ \\
\hline ENN_MN & $.412^{* *}$ & $.527^{* *}$ & $.345^{*}$ & $.344^{*}$ \\
\hline
\end{tabular}

Table 2. Correlation analysis on surface net radiation and landscape metrics across seasons

\subsection{Partial Pearson Correlation Analysis}

Composition metrics, PLAND2 and PLAND5, were taken as the controlled variables prior to configuration metrics. While after partial Pearson, all of the factors in Table 2 lost their consistence of significant correlation with surface net radiation. Since the table is a little too width to fit this format of paper, we did not show the specific numbers here.

\subsection{Variance partitioning}

We further conducted stepwise regressions to find the real consistently significant factors in the landscape metrics- surface net radiation associations on each date, as well as their relative predictive importance. Models were constructed for each season, with mean surface net radiation as the dependent variable and the consistently significant factors acquired above as independent variables. Finally, variance partitioning was also carried out based on the stepwise regression models (Anderson and Gribble 1998; Heikkinen et al. 2005). It was used to quantify and compare the relative importance of composition and configuration metrics in explaining the variation of LST between different dates across seasons.

As shown in Table 3, the spatial composition of land cover pattern shows significant influence on surface net radiation. The proportion of bare land (PLAND2) and the proportion of forest land (PLAND5) are effective and important factors which affect the changes of surface net radiation all the year round. But the spatial allocation of land cover pattern has no significant influence on surface net radiation.

Moreover, the proportion of forest land is more capable for explaining surface net radiation than the proportion of bare land across all the seasons except spring. Its total annual explanatory ability is better than the latter.

\begin{tabular}{|c|c|c|}
\hline Season & Metrics & Variations explained \\
\hline \multirow{2}{*}{ Autumn } & PLAND2 & .340 \\
\cline { 2 - 3 } & PLAND5 & .437 \\
\hline \multirow{2}{*}{ Winter } & PLAND2 & .500 \\
\cline { 2 - 3 } & PLAND5 & .549 \\
\hline \multirow{2}{*}{ Spring } & PLAND2 & .508 \\
\cline { 2 - 3 } & PLAND5 & .384 \\
\hline \multirow{2}{*}{ Summer } & PLAND2 & .235 \\
\cline { 2 - 3 } & PLAND5 & .483 \\
\hline
\end{tabular}

Table 3. Results of variance decomposition

\section{CONCLUSIONS}

At both class and landscape levels, this paper comprehensively analyzed the temporal and spatial variations of the surface net radiation as well as the effects of land cover pattern on it in Xiamen from a multi-seasonal perspective. The results showed that Xiamen's surface net radiation is the maximum in summer, followed by spring, autumn. The surface net radiation in winter is the minimum. Net radiation flux is higher for water and forestland and is lower for built-up land and bare land, etc. The spatial composition of land cover pattern shows significant influence on surface net radiation. The proportion of bare land and the proportion of forest land are effective and important factors which affect the changes of surface net radiation all the year round. But the spatial allocation of land cover pattern has 
no significant influence on surface net radiation. Moreover, the proportion of forest land is more capable for explaining surface net radiation than the proportion of bare land. Its total annual explanatory ability is better than the latter.

So the proportion of forest land is the most important and continuously effective factor which affects and explains the cross-seasonal differences of surface net radiation. This study is helpful in exploring the formation and evolution mechanism of urban heat island. It also gave theoretical hints and realistic guidance for urban planning and sustainable development.

\section{ACKNOWLEDGEMENTS}

This study was supported by the National Natural Science Foundation of China (No.41371392) and the Major Special Project-the China High-Resolution Earth Observation System. We wish to thank Professor Jianguo Wu and Dr. Juanjuan Zhao for their helps on this research.

\section{REFERENCES}

Grimm, N., Faeth, S., Golubiewski, N., Redman, C., Wu, J., Bai, X., Briggs, J., 2008. Global change and the ecology of cities. Science, 319, pp.756-760.

Arnfield, A., 2003. Two decades of urban climate research: A review of turbulence, exchanges of energy and water, and the urban heat island. International Journal of Climatology, 23, pp. $1-26$.

Liu, Y., Shintaro, G., Zhuang D., Kuang W., 2012. Urban surface heat flux inversion based on infrared remote sensing and the relationship with land cover. Acta Geographica Sinica, 01, pp. 101-112

Xiamen Bureau of Statistics, 2013. 2013 Year book of Xiamen special economic zone. China Statistics Press (in Chinese), Beijing, China.

Zhao, J., Dai, D., Lin, T., Tang, L, 2010a. Rapid urbanisation, ecological effects and sustainable city construction in Xiamen. International Journal of Sustainable Development and World Ecology, 17, 271-272.

Zhao, X., Huang, J., Ye, H., Wang, K., Qiu, Q., 2010 b. Spatiotemporal changes of the urban heat island of a coastal city in the context of urbanisation. International Journal of Sustainable Development and World Ecology, 17, 311-316.

Yamaguchi, Y., Kato, S., 2005. Analysis of urban heat-island effect using ASTER and ETM+ Data: Separation of anthropogenic heat discharge and natural heat radiation from sensible heat flux. Remote Sensing of Environment, 99, pp. 4454.

Kato, S., Liu, C., Sun, C., et al, 2012. Comparison of surface heat balance in three cities in Taiwan using Terra ASTER and Formosat-2 RSI data. International Journal of Applied Earth Observation \& Geoinformation, 18(18), pp. 263-273.

Liang, S., 2001. Narrowband to broadband conversions of land surface albedo I: Algorithms. Remote Sensing of Environment, 76(2), pp. 213-238.

Li, X., Zhou, W., Ouyang, Z., 2013. Relationship between land surface temperature and spatial pattern of greenspace: What are the effects of spatial resolution? Landscape and Urban Planning, 114, pp. 1-8.

Zhou, W., Huang, G., Cadenasso, M., 2011. Does spatial configuration matter? Understanding the effects of land cover pattern on land surface temperature in urban landscapes. Landscape and Urban Planning, 102, pp. 54-63.

Anderson, M., Gribble, N., 1998. Partitioning the variation among spatial, temporal and environmental components in a multivariate data set. Australian Journal of Ecology, 23(2), pp. 158-167

Heikkinen, R., Luoto, M., Kuussaari, M., Pöyry, J., 2005. New insights into butterfly-environment relationships using partitioning methods. Proceedings of the Royal Society of BBiological Sciences, 272(1577), pp. 2203-2210 